\title{
Brain abscess associated with persistent left superior vena cava in a 58-year-old man
}

\author{
Thomas Barba, ${ }^{1}$ Judith Karsenty, ${ }^{1,2}$ Loïc Boussel, ${ }^{2-4}$ Tristan Ferry ${ }^{1,2,5}$
}

${ }^{1}$ Service de Maladies Infectieuses et Tropicales, Hôpital de la Croix-Rousse, Hospices Civils de Lyon, Lyon, France

${ }^{2}$ Université Claude Bernard Lyon 1, Lyon, France ${ }^{3}$ Service de Radiologie, Hôpital de la Croix-Rousse, Hospices Civils de Lyon, Lyon, France ${ }^{4}$ CREATIS, CNRS, UMR 5515, INSERM U630, Lyon, France ${ }^{5}$ Centre International de Recherche en Infectiologie CIRI, Inserm U1111, CNRSUMR5308, ENS de Lyon, UCBL1, Lyon, France

\section{Correspondence to} Dr Tristan Ferry, tristan.ferry@univ-lyon1.fr

\footnotetext{
To cite: Barba T, Karsenty J, Boussel L, et al. BMJ Case Rep Published online: [please include Day Month Year] doi:10.1136/bcr-2013009017
}

\section{DESCRIPTION}

A 58-year-old patient with no medical history was diagnosed brain abscess (figure 1 A) 2 weeks after non-invasive dentistry (tartar removal, only). Biopsy showed pus, with Fusobacterium nucleatum in cultures. Blood cultures were negative. There was no clinical evidence for a Rendu-Osler-Weber disease (also called hereditary haemorrhagic telangiectasia). Antibiotics were administered during 6 weeks, with good efficacy. Echocardiography showed no sign of infective endocarditis. Contrast-enhanced echography highlighted a right-to-left shunt. Contrast-enhanced CT showed persistent left superior vena cava (PLSVC), coming from left jugular vein and draining directly into the left atrium (figure 1B,C).

Intracardiac and extracardiac shunts, such as intracerebral arteriovenous malformations associated with Rendu-Osler-Weber disease, are great providers of brain abscesses. ${ }^{12}$ The PLSVC is a common thoracic venous malformation, ${ }^{3}$ with a prevalence of $0.3-$ $0.5 \%$ of the population. Superior cava venous system derives from the embryological cardinal veins. The left cardinal vein usually regresses (its distal portion giving birth to the coronary sinus), while the right one becomes the definitive superior cava vena. PLSVC is due to the non-regression of the left cardinal vein, often associated with anomalies or missing of the coronary venous sinus. In most of the cases, the PLSVC drains into the right atrium, through the coronary sinus. Here, the PLSVC drains into the left atrium, resulting in a right-to-left shunt. As a consequence, the non-invasive dental procedure was probably associated with low-grade and shortduration F. nucleatum bacteraemia, which was not stopped by the pulmonary filter, but migrated right through the left cavities to the brain. A surgical closure of this right-to-left shunt is scheduled.

In a patient with cerebral abscess, intracardiac and extracardiac shunts have to be suspected, such as intracerebral arteriovenous malformations (associated with Rendu-Osler-Weber disease), atrial septal defect or thoracic venous malformation.

\section{Learning points}

- Persistent left superior vena cava (PLSVC) is a common thoracic venous malformation.

- PLSVC could drain directly into the left atrium, resulting in a right-to-left shunt.

- PLSVC could be associated with brain abscess following non-invasive dentistry.

\section{Acknowledgements We acknowledge Dr Olivier Revel who participated in the patient care.}

Contributors All authors participated in the patient care, the literature review and the writing of the article.

Competing interests None.

Patient consent Obtained.

Provenance and peer review Not commissioned; externally peer reviewed.
A

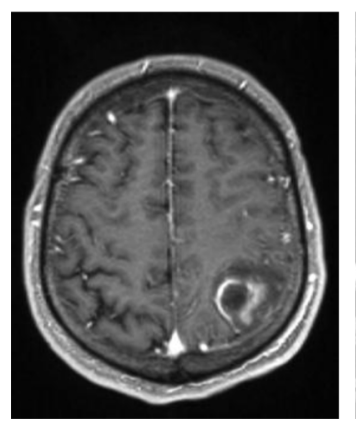

B

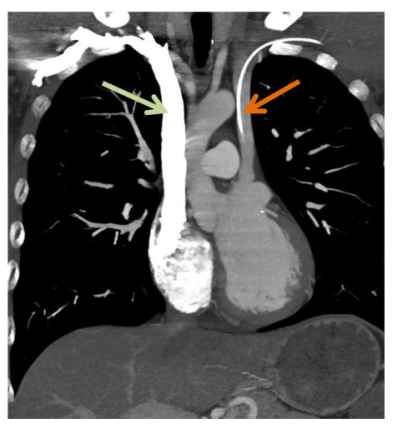

C

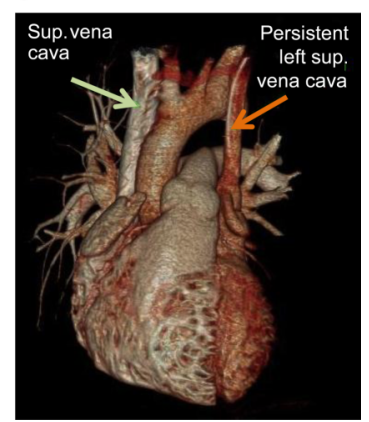

Figure 1 Cerebral MRI showing a $27 \mathrm{~mm}$ large left parietal abscess (A); contrast-enhanced chest $\mathrm{CT}$ in coronal multiplanar reconstruction (B) and three-dimensional reconstruction (C) showing the normal right superior vena cava (green arrow in B and C) and a persistent left superior vena cava (with central venous catheter, red arrow in B and C), draining into the left atrium. 


\section{REFERENCES}

1 Fukuoka T, Dembo T, Nagoya $H$, et al. Factors related to recurrence of paradoxical cerebral embolism due to patent foramen ovale. J Neurol 2012;259:1051-5.

2 Horiuchi Y, Kato Y, Dembo T, et al. Patent foramen ovale as a risk factor for cryptogenic brain abscess: case report and review of the literature. Intern Med 2012;51:1111-14
3 Duymus $M$, Yesilkaya $Y$, Orman $G$, et al. Persistent left superior vena cava draining to the left atrium: a case report and review of the literature. Polish J Radiol 2012;77:65-6

Copyright 2013 BMJ Publishing Group. All rights reserved. For permission to reuse any of this content visit

http://group.bmj.com/group/rights-licensing/permissions.

BMJ Case Report Fellows may re-use this article for personal use and teaching without any further permission.

Become a Fellow of BMJ Case Reports today and you can:

- Submit as many cases as you like

- Enjoy fast sympathetic peer review and rapid publication of accepted articles

- Access all the published articles

- Re-use any of the published material for personal use and teaching without further permission

For information on Institutional Fellowships contact consortiasales@bmjgroup.com

Visit casereports.bmj.com for more articles like this and to become a Fellow 